\title{
A fundação de Belo Horizonte: ordem, progresso e higiene, mas não para todos
}

\author{
The foundation of Belo Horizonte: \\ order, progress and hygiene, but not for all
}

Patricia Capanema Alvares Fernandes [I]

\begin{abstract}
Resumo
O plano de Belo Horizonte, capital inaugurada no fim do século XIX, teve ordem, progresso e higiene como premissas básicas. Todavia, a cidade apresenta, desde suas origens, um padrão peculiar de segregação socioespacial. Essa condição tem sido atribuída a seu plano, que previa a construção de uma zona urbana elitista, expulsando antigos moradores e imigrantes pobres para os subúrbios desorganizados e sem higiene, assim como áreas de risco e ambientalmente frágeis. Esta pesquisa histórica revela quais mecanismos e práticas resultaram em tal segregação socioespacial, agindo além do plano e em consequência dele, ao mesmo tempo que desafia dicotomias tais como centro rico/ periferia pobre que têm dominado a historiografia sobre Belo Horizonte, revelando uma realidade muito mais complexa.
\end{abstract}

Palavras-chave: higiene; planejamento; história urbana; legislação.

\begin{abstract}
The plan for Belo Horizonte, founded at the turn of the $19^{\text {th }}$ century, was premised by order, progress and hygiene. The city has displayed, however, a peculiar pattern of social-spatial exclusion since its beginnings. This pattern has be traced back to the plan, as it foresaw the construction of an elitist urban area in replacement of the existing village, evicting former residents and poor newcomers and relegating them to the unorganized, unhygienic suburbs as well as to at-risk and environmentally fragile areas. This historiographic research reveals which mechanisms and practices led to such socialspatial segregation, working outside and as a result of its plan, while challenging simplistic "rich-center/ poor-periphery" dichotomies that have dominated Belo Horizonte's historiography, unveiling instead a much more complex reality.
\end{abstract}

Keywords: hygiene; planning; urban history; legislation. 


\section{Introdução}

No final do século XIX, ideais de ordem, progresso e higiene guiaram o planejamento urbanístico e a fundação de Belo Horizonte, a nova capital de Minas Gerais. Enquanto ordem e progresso constituíam os emblemas da Nova República, higiene era a grande obsessão do momento, em repercussão às epidemias e pestes que haviam devastado a Europa. Foi também uma reação ao modelo de urbanização colonial vigente até então, representado pela cidade de Ouro Preto, a antiga capital do estado.

Tais premissas orientaram a formulação de uma planta para a área urbana da cidade na forma de grelha, pressupondo isometria e igualdade. Contudo, considerando que o plano para Belo Horizonte foi muito além do urbano - a saber, simultaneamente urbano, suburbano e rural - e considerando, principalmente, os limitados recursos para a construção da cidade, ordem, progresso e higiene não foram para todos. Saúde, portanto, também não foi para todos. As diferenças entre urbano e suburbano já presentes no plano de 1895 para Belo Horizonte, da autoria do engenheiro Aarão Reis, foram posteriormente aprofundadas pela desigual distribuição de infraestrutura básica pelo território, tais como esgoto e água potável.

Apoiada em pesquisas históricas, a análise a seguir expõe os mecanismos e práticas das primeiras décadas da capital que resultaram em diversas formas de segregação socioespacial, atuando para além do plano ou como resultado deste. Ao mesmo tempo, a análise desafia o reducionismo de dicotomias, tais como centro-rico versus periferia-pobre, que dominam a historiografia de Belo Horizonte, ao revelar uma realidade muito mais complexa.
Uma das muitas interpretações possíveis sobre a fundação de Belo Horizonte como a nova capital de Minas Gerais, em 1897, retrata-a como um reflexo de importantes acontecimentos da segunda metade do século XIX no Brasil e no mundo. Na escala nacional, a cidade surge poucos anos após a Proclamação da República, em 1889, e a abolição da escravatura no ano anterior. Influenciando direta ou indiretamente a criação de uma nova cidade, tais eventos representam, sem dúvida, o apogeu de um período de amplas transformações políticas, econômicas e sociais no Brasil. Em escala global, Belo Horizonte surge algumas décadas após as radicais reformas de Haussmann, em Paris, que mudaram o curso do urbanismo para sempre. ${ }^{1}$ Duas outras capitais certamente tiveram papel fundamental na história da criação de Belo Horizonte: Washington D.C., inaugurada um século antes, e a argentina La Plata, esta precedendo Belo Horizonte em apenas uma década.

A construção de Belo Horizonte foi interpretada por diversos autores como um empreendimento significativo dentro do projeto republicano. Não apenas pelo plano, mas, sobretudo, pela construção, a cidade foi vista como a representação material do poder do Estado, incorporando, em um gesto, os ideais republicanos de ordem e progresso (Le-Ven, 1977; Magalhães e Andrade, 1989; Paula e Monte-Mór, s/d). Muitas pesquisas foram direcionadas à contextualização política da fundação da cidade, além da associação ao positivismo, racionalismo e urbanismo barroco (Aguiar, 2006; Faria, 1985; Gomes e Lima, 1999; Lemos, 1998; Magalhães e Andrade, 1989; Resende, 1974). Ainda, muitas pesquisas interpretaram o plano de Belo Horizonte como exemplar da transferência de modelos da Europa e da América do Norte, seja pelos 
ideias positivistas incorporados em seu plano e construção, seja pela forma urbana ou pelas soluções técnicas adotadas (Salgueiro, 2001). 0 presente artigo distancia-se das ideias de "inspiração", "cópias distorcidas" ou "transferência de modelos", propondo uma leitura sobre a fundação de Belo Horizonte baseada nos três pilares ideológicos que a sustentaram desde a idealização até a materialização: ordem, progresso e higiene. Ordem e progresso, no pensamento positivista e nos ideais republicanos, significavam não somente o ordenamento físico e o progresso econômico, mas, acima de tudo, ordem social e progresso social. No ambiente urbano, estes só seriam possíveis com a garantia da saúde de seus habitantes, para a qual a higiene era elemento-chave.

Por um lado, a experiência da industrialização nas cidades europeias e as insustentáveis condições de vida dos trabalhadores, expostas por Engels, e ainda as muitas pragas e crises sanitárias em Londres e Paris tornaram a higiene um ingrediente fundamental para as cidades (Choay, 2005). Por outro, a industrialização também produziu uma visão otimista do futuro, sob a dominação das ideias de progresso. Nessa linha de pensamento, racionalismo, ciência e tecnologia eram chaves para solucionar os problemas advindos da relação homem-meio ambiente (ibid., p. 8). Assim, quando as relações entre homem e cidade causassem problemas ambientais, tais como a propagação de doenças, a ciência e a tecnologia poderiam retomar o equilíbrio.

Desse modo, higiene, ordem e progresso tornaram-se onipresentes nos discursos dos engenheiros, planejadores, políticos e administradores envolvidos no planejamento e na construção de Belo Horizonte, bem como de outras cidades da época. Nesse caso em particular, ordem e higiene levaram à construção de uma cidade em parte geométrica, interrompida por amplos espaços vazios e áreas verdes - características do que Choay (ibid.) classificou como modelo progressista. Entretanto, em 1895, quando Belo Horizonte foi planejada, a industrialização ainda não era uma realidade nas cidades brasileiras. Tais princípios urbanísticos foram, portanto, transpostos da Europa e adaptados para os problemas e motivações locais. Nesse sentido, a aversão à cidade colonial orgânica e não planejada (tal como Ouro Preto, a antiga capital), no contexto da inauguração da república, foi fundamental.

Outro aspecto do positivismo pontualmente incorporado pelo autor do plano de Belo Horizonte foi a questão do progresso social e material. Na análise de Salgueiro (1997), ao construir o que chamou de uma "biografia individual", as leituras e os textos produzidos por Aarão Reis claramente demonstram suas inclinações para o positivismo e para o pensamento francês, bem como seu interesse pelas causas do progresso, o amor pela humanidade e o bem-estar público, consoante com os textos iluministas que lia (ibid., p. 28). Porém, tal preocupação positivista com o bem-estar da população não foi além das intenções políticas e do discurso, quando se tratou da construção da cidade, como veremos a seguir.

As próximas seções irão demonstrar em que medida a higiene foi uma ideia onipresente na fundação de Belo Horizonte, desde o surgimento das primeiras ambições políticas para a criação de uma nova capital. Como dito, não era uma exclusividade do pensamento de Aarão Reis, mas parte de um consenso geral - que inclui políticos - sobre como construir cidades ideais. Mais adiante, o artigo irá demonstrar, através de uma montagem ${ }^{2}$ de ações, leis e eventos, 
que o tripé almejado - ordem, progresso e higiene - para a capital não foi igualmente distribuído pelo território. Gradualmente, o plano geométrico guiado pela razão começa a ganhar novas texturas que irão se perpetuar através da história de Belo Horizonte, sendo a exclusão socioespacial a mais problemática.

\section{Antecedentes: "ordem e higiene" como lemas para a nova capital}

Alguns dias após a Proclamação da República Federativa do Brasil (1889), o decreto n. 7 (Brasil, 1889) concedeu competências especiais para os governos dos estados até a elaboração definitiva da Constituição Nacional, promulgada somente em 1891. Uma dessas competências era: "§1ㅇ: Estabelecer a divisão civil, judicial e eclesiástica do respectivo Estado e ordenar a mudança de sua capital para logar que mais convier"3 (Brasil, 1889). Tal decreto instigou discussões fervorosas nas Assembleias Constituintes do Estado de Minas Gerais entre 1890 e 1891. Os debates culminaram na elaboração do artigo 117 do projeto constitucional do estado, determinando a transferência da capital para local a ser escolhido no Vale do Rio das Velhas. Como demonstrado no relato histórico de Linhares (1905), o projeto para a nova capital de Minas Gerais não foi nenhuma novidade, tendo origens já na Inconfidência Mineira e reemergindo diversas vezes na história.

Todavia, antes mesmo que a questão se tornasse um tópico de discussão no Congresso, quando a ideia da transferência da capital ressurgiu, o governador já havia designado uma comissão para estudar alguns locais ao longo do Vale do Rio das Velhas: Lagoa Santa, Quinta do Sumidouro, Fazenda do Jaraguara, Barra do Jequitibá, Sete Lagoas, Fazenda do Campo Alegre, Matozinhos e Bello Horisonte ${ }^{4}$ (ibid., p. 55). Em outubro de 1890, o relatório produzido pela comissão e assinado por Herculano Penna apontou o Arraial de Bello Horisonte ${ }^{5}$ como o melhor local. Tal relatório circulou nas mãos de congressistas e jornais, tendo sido frequentemente mencionado nos debates nas Assembleias Constituintes (O Jornal de Minas, 1891). Os rumores de que o Arraial seria a localidade escolhida para a nova capital se espalharam rapidamente, conforme publicação de nota em um jornal local de Ouro Preto, O Jornal de Minas. Este jornal esteve em circulação somente entre os anos 1890 e 1891, publicando quase que diariamente visões bastante parciais sobre a mudança da capital, uma vez que os editores não escondiam suas oposições ao projeto. É interessante notar que o criticismo incluía deboches direcionados à população do Arraial de Bello Horisonte, conhecidos por sofrerem de bócio, provavelmente devido à falta de iodo. A intenção era questionar a adequação da localização da nova capital, uma vez que faltava a condição considerada mais essencial na época: higiene. ${ }^{6}$

Apesar de o projeto de transferência da capital não ter sido amplamente discutido no Congresso até meados de 1891, tais especulações sobre sua futura localização não eram totalmente infundadas. Em março de 1891, o então presidente do estado dr. Augusto de Lima chegou a redigir um decreto que transferiria a capital para o Arraial de Bello Horisonte, que nunca foi publicado. Em 7 de abril do mesmo 
ano, sua mensagem dirigida ao Congresso Constituinte $^{7}$ enfatizava a necessidade de mudança da capital, apontando Bello Horisonte como o local mais favorável.

0 artigo 117 do projeto constitucional, que determinava a transferência da capital para um ponto no Vale do Rio das Velhas, teve origem em uma proposta de lei apresentada pelo congressista dr. Augusto Clementino em 24 de março de 1891. Tal proposta não era senão um eco do projeto apresentado pelo sr. Paraízo em 1867, com os dizeres:

Fica mudada a capital do Estado para um ponto central no vale do Rio das Velhas, que se preste à edificação de uma grande cidade com as indispensáveis condições higiênicas. §1ㅇ- Esta mudança se realizará no prazo máximo de quatro anos, etc. (n.d. apud Linhares, 1905, p. 60)

Três atributos essenciais para a nova capital podem ser extraídos dessa proposta. Primeiramente, centralidade era uma característica importante. Segundo, deveria se tornar uma grande cidade. Finalmente, higiene era uma questão primordial. Tais aspectos formam a contraimagem das características de Ouro Preto: isolada, de difícil topografia e anti-higiênica, na opinião do congressista. Dessa forma, é obvio que a prioridade dada à higiene na construção da nova cidade, geralmente atribuída à mente positivista de Aarão Reis, era, na realidade, uma apreensão geral dentre políticos da época, alguns anos antes do engenheiro entrar em cena.

A escolha do local para a nova capital instigou grande controvérsia nas Assembleias Constituintes, o que não cabe a este artigo tratar extensamente. Depois de Iongas discussões, o projeto para a nova capital foi finalmente aprovado, mas chegar a um consenso sobre sua localização a tempo para a aprovação da Constituição do Estado revelou-se uma tarefa impossível. 0 texto constitucional, aprovado em junho de 1891, incluiu, portanto, o artigo 13 das disposições transitórias - com texto quase idêntico ao artigo 117 do projeto constitucional -, determinando a transferência da capital sem, no entanto, designar uma localização. Em outubro do mesmo ano, tal artigo se tornou a lei n. 1, adicional à Constituição. Em 1892, o novo presidente do Estado, Afonso Penna, criou uma comissão especial para estudar e finalmente escolher - local para a capital, intitulada "Comissão D'Estudos das Localidades Indicadas para a Nova Capital" (que será doravante referida como "Comissão de Estudos"). Após muitas discussões, as cinco localidades escolhidas para as pesquisas foram: Bello Horisonte, Várzea do Marçal, Barbacena, Juiz de Fora e Paraúna.

A Comissão de Estudos realizou um levantamento meticuloso das cinco localidades, um trabalho de fato mais próximo ao campo da estatística do que ao da engenharia. Além das condições físicas levantadas em cada localidade - topografia, hidrografia, acessos, vias -, o relatório final apresentou diversos gráficos, tabelas e dados sobre demografia, temperatura, regime de chuvas, salubridade, boletins médicos, etc. (Capital, 1893). As cinco localidades foram comparadas segundo parâmetros específicos, considerados de maior importância para o estabelecimento de uma cidade para 200.000 habitantes. Os capítulos do relatório foram elencados de acordo com: I) Condições naturais de salubridade; II) Abastecimento de água; III) Esgoto; IV) Edifícios e construções; V) Recursos de vida; VI) Iluminação pública e particular; VII) Transporte; e VIII)Balanço geral (de gastos mínimos). É importante notar que 
a comissão era composta, além de engenheiros, por um médico higienista, dr. José Ricardo Pires de Almeida. Assinando um dos anexos do relatório final, o médico analisa, para cada localidade, os seguintes aspectos: a avaliação final, sob o ponto de vista do Movimento Higienista Social, análise físico-química e bacteriológica das águas, doenças mais frequentes, mortalidade. No final do seu relatório, o médico higienista comparou e classificou as localidades de acordo com esses parâmetros, com o propósito de orientar a decisão final.

Finalmente, tendo o relatório da Comissão de Estudos em mãos- e após tantas outras calorosas discussões e votações -, Bello Horisonte, no vale do Rio das Velhas, foi a escolha final - e também a primeira - para a localização da nova capital. Em 17 de dezembro de 1893, o primeiro artigo da lei n. 3 adicional à Constituição aponta, enfim, Bello Horisonte como a localidade escolhida para a nova capital. A lei também autoriza o governo a mandar organizar o plano definitivo da nova cidade, de acordo com algumas bases. Destas, podemos destacar as que levaram a uma distribuição desigual de pessoas e recursos:

a divisão do terreno em lotes destinados a edificações urbanas, a quintas ou a chácaras, com a determinação de preços de cada chategoria, arttendendo a sua collocação, proximidade do centro da cidade e outras condições que possam influir no respectivo valor; [...] A proceder à desapropriação dos terrenos particulares, comprehendidos na planta que for approvada" [significando, portanto, a total extinção do antigo Arraial de Bello Horisonte com o despejo de seus moradores]. A estabelecer, em regulamento os planos, condições hygienicas e architectonicas que devem presidir às edificações, assim como o tempo e modo das concessões; [...]); Igualmente promoverá a construção de casa em condições hygiênicas e de aluguel barato para operários; a conceder a título gratuito aos actuaes funcionários estadoaes que por lei têm residência obrigatória na Capital [...]; a conceder a título gratuito a cada um dos actuaes proprietários de casas em Ouro Preto [...]. (Commissão Constructora da Nova Capital, 1895, p. 26)

Logo, dois anos antes do plano de Aarão Reis ser aprovado e os primeiros lotes da cidade serem distribuídos, a lei n. 3 já havia delineado duas importantes tendências para a capital. Em primeiro lugar, higiene e estética eram atributos tão indispensáveis à cidade que deveriam ser regulados e, portando, obrigatórios. Em segundo, o governo deveria reservar e distribuir lotes para uma categoria especial de futuros moradores, bem como determinar os preços para as outras áreas. Combinadas, essas duas inclinações se tornaram as condições básicas determinantes de um tipo peculiar de segregação socioespacial em Belo Horizonte, definida por um certo controle de qualidade higiênica e arquitetônica - e pelo valor dos lotes. Posteriormente, a elaboração do plano, a construção da cidade e finalmente a ocupação do perímetro do plano e além adicionaram novas camadas e texturas para a segregação socioespacial que vemos em Belo Horizonte até os dias atuais. A próxima seção irá detalhar a constelação de planos, leis, regulações e eventos que contribuíram para essas condições. 


\section{Planejando isometria, construindo diferença}

Em maio de 1895, Aarão Reis, na posição de chefe da CCNC - Comissão Constructora da Nova Capital -, publicou a planta para a Cidade de Minas, hoje Belo Horizonte. Ao apresentar uma sobreposição de duas grelhas ortogonais, seu plano, tal qual egresso da Escola Politécnica, era carregado de referências a circulação, fluidez, acessibilidade, velocidade, higiene, etc. $\mathrm{Na}$ obra Seeing Like a State (1998), o economista político James Scott elencou alguns aspectos importantes sobre o uso da ordem geométrica para o planejamento de assentamentos humanos. Ele afirma que tal ordem é mais evidente vista de cima e de fora - ou seja, acima do nível da rua -, uma vez que essa perspectiva permite a legibilidade para o estrangeiro. Como uma cidade totalmente nova, era importante que Belo Horizonte apresentasse certa clareza, visto que a cidade foi concebida para os estrangeiros e não para os residentes locais do antigo Arraial. Geometria, homogeneidade e uniformidade eram aspectos convenientes para as propriedades urbanas, tornando-as um produto padronizado no mercado.

Entretanto, enquanto um novo ordenamento espacial racional teria bastante utilidade para as autoridades, o mesmo não se pode dizer a respeito dos habitantes. Nesse sentido, Scott afirma que "devemos permanecer agnósticos sobre as conexões entre a ordem espacial e a experiência social"8 (ibid., p. 58). Em outras palavras, a ordem espacial das ruas não implica necessariamente uma ordem social, ou seja, melhores condições de vida para seus habitantes. Assim, a ordem geométrica imposta para o centro de Belo Horizonte, que será apresentada mais detalhadamente adiante, não significou melhores condições de vida para todos. De toda maneira, o plano só previa tal ordem para uma parte da cidade (a zona urbana), provavelmente em antecipação à incapacidade estatal de ocupar-se da urbanização completa da cidade.

Como abordado anteriormente, a prioridade dada a ordem, fluxos e higiene é frequentemente atribuída a uma decisão pessoal do engenheiro Aarão Reis, considerando suas inclinações positivistas e seu treinamento técnico (Salgueiro, 2001). No entanto, tais interpretações frequentemente desconsideram o peso do decreto n. 803, de 11 de janeiro de 1895, nessas escolhas, publicado quatro meses antes da publicação do plano de Reis, e que estabeleceu as bases para a "Planta da Cidade de Minas". Tal decreto foi assinado pelo engenheiro Francisco Sá, que ocupava o cargo de chefia da Secretaria de Agricultura, a repartição então responsável pela construção da cidade. Em seu segundo artigo, o decreto determina: "Art. 2ㅇ: A sua área será dividida em secções, quarteirões e lotes, com espaços, avenidas e ruas necessárias para a rápida e fácil comunicação dos seus habitantes, boa ventilação e hygiene" (Minas Geraes. Orgão Official dos Poderes do Estado, 1895a). A racionalidade do plano e a prioridade dada à circulação de ar e de pessoas já estavam, portanto, determinadas por esse decreto, da mesma maneira que a higiene era uma condição presente desde os discursos dos congressistas sobre a transferência da capital administrativa do estado por volta de 1890-1891, como visto acima.

Construir uma cidade a partir do zero demanda serviços de urbanização dos mais básicos, tais como cortes e aterros, arruamento, abastecimento de água e esgoto, 
teoricamente, todos necessários de imediato. No contexto de recursos limitados, como era o caso de Belo Horizonte, alguns desses serviços tiveram prioridade sobre outros. Havia, portanto, duas categorias distintas de infraestruturas: aquelas demandando mínimo investimento para o estabelecimento instantâneo de uma cidade minimamente funcional que poderia começar a receber a nova população; e os investimentos máximos de longo prazo que iriam, gradualmente, construir o legado material da cidade. Os investimentos de longo prazo foram, então, a instalação de redes de esgoto, água e eletricidade, enquanto, a curto prazo, as casas expropriadas do Arraial foram disponibilizadas para os engenheiros e outros profissionais envolvidos na construção da capital.

0 decreto n. 680 de 1894, que precedeu à aprovação do plano para Belo Horizonte, distinguiu o plano geral daquele que seria implementado em seu terceiro artigo.

O projeto geral da nova capital será delineado sobre a base de uma população de 200.000 habitantes, e sobre esta mesma base será efetuada a divisão e demarcação dos lotes; as obras, porém, a executar desde já, serão projetadas e orçadas sobre a base de uma população de 30.000 habitantes, devendo, entretanto, os respectivos projetos ser organizados de forma a permitirem o natural desenvolvimento das obras executadas à proporção que for aumentando a população. (Minas Gerais, 1894)

Logo, enquanto o plano geral previa uma população de 200.000 habitantes, simultaneamente ocupando as zonas urbana, suburbana e rural, apenas parte da construção seria executada pelo Estado em um primeiro momento. A faixa a ser entregue pela CCNC para a inauguração da cidade conteria somente os elementos necessários para o funcionamento da capital: a estação de trem, alguns edifícios públicos, parte da grelha contendo lotes e casas para os funcionários públicos transferidos. Visto que a lei n. 3 Adicional à Constituição havia estabelecido um limite de quatro anos para a transferência da capital, Belo Horizonte foi precocemente inaugurada em 12 de dezembro de 1897. Nessa data, apenas uma pequena parte do plano havia sido executada, enquanto a cidade permaneceu como um canteiro de obras durante muitos anos (Barreto, 1996).

A instalação de redes de infraestrutura, tais como ferrovia, água e esgoto, era não somente crucial para a urbanização e o conforto da futura população de Belo Horizonte, mas, sobretudo, um importante emblema da modernização e do progresso. Nesse sentido, a construção da capital simbolizava a formação da metrópole moderna, que, assim como em outras cidades, "se tornou um celeiro para inovação e sorvedouro de mudanças sociais, culturais e econômicas, enquanto as noções de velocidade, luz, eletricidade e comunicações estavam sendo construídas"9 (Graham e Marvin, 2001). A construção da cidade tornou-se, assim, o terreno ideal para que engenheiros experimentassem o progresso tecnológico. É significativo notar, portanto, que a iluminação pública em Belo Horizonte foi entregue alguns dias antes de sua inauguração, enquanto as instalações de água e esgoto ainda estavam incompletas (Singer, 1968). Visto que a prioridade foi dada às infraestruturas visíveis, era mais importante parecer pronta, do que de fato estar pronta.

Consequentemente, os investimentos voltaram-se para aqueles elementos necessários ao funcionamento imediato e também à imagem simbólica da nova cidade: ferrovia, 
edifícios públicos e a execução da faixa para 30.000 habitantes. Em paralelo, o Estado também investiu nas colônias agrícolas - estruturas menos visíveis e menos permanentes, uma vez que logo foram urbanizadas - que tiveram uma importância fundamental no desenvolvimento suburbano de Belo Horizonte (ver mais adiante). Analisando a ocupação da cidade em 1928-1929, a partir de dados cadastrais (Belo Horizonte, 1929), as consequências desses investimentos são evidentes, visto que a lógica espacial da área até então edificada foi determinada por dois eixos: o da faixa construída na zona urbana e o outro ao longo do vale do Ribeirão Arrudas, ou seja, ao longo da ferrovia. Inicialmente implementada para conectar Belo Horizonte à Sabará, a leste, a ferrovia foi logo expandida para a direção oeste, uma vez que já havia uma massa de população vivendo nessas áreas.

Logo, o que parecia inicialmente um plano isométrico começa a ganhar novas texturas, na medida em que infraestruturas visíveis e invisíveis foram implementadas apenas em algumas - redes de água e esgoto sob o solo e redes de ruas e eletricidade acima. Através do poder do Estado, o arraial foi se transformando em cidade, permitindo o assentamento gradual dos imigrantes. Seguindo a infraestrutura, a cidade começa a se desenvolver primeiro nas partes mais baixas, próximas à estação ferroviária, na região que se veio a se tornar o centro da cidade. Aos poucos, a elite local começou a ocupar a encosta suave que termina no Palácio Presidencial, enquanto a população mais pobre espalhava-se rapidamente nas encostas mais íngremes, ao outro lado do vale do Arrudas, na zona suburbana, ao longo da ferrovia e nas colônias agrícolas (Guimarães, 1991; Barreto, 1996). A distribuição dos lotes e das pessoas e a implementação de infraestrutura foram, portanto, fatores decisivos para a segregação socioespacial que se inaugurou em Belo Horizonte.

Apesar de Belo Horizonte ter sido concebida para ser o centro administrativo do estado de Minas Gerais, habitada por funcionários públicos, é interessante notar que a nova cidade não apagou de um só gesto o Arraial e seus moradores, participantes ativos da construção da cidade, apesar da posição desprivilegiada. Relatos importantes da coexistência entre os moradores do arraial e os novos construtores foram fornecidos pelo padre Francisco Martins Dias (1897) e, depois dele, pelo historiador Abílio Barreto (1996), ambos testemunhas oculares da construção da cidade. Antes que os "moradores oficiais" chegassem - servidores públicos e políticos para quem foram cedidos lotes e mais tarde concedidas casas no estilo eclético -, a população de Belo Horizonte foi se formando, camada por camada, por moradores do Arraial, engenheiros, jornalistas, construtores, vendedores e até camponeses. Estes vivenciaram juntos a diária demolição e construção da nova cidade, enquanto seu espaço era algo indefinido entre um antigo Arraial e a nova capital administrativa do estado. É importante considerar, portanto, a coexistência de arraial e cidade, camponeses e servidores.

Após a aprovação oficial do plano, em abril de 1895, a CCNC iniciou a distribuição de lotes em hastas (leilões) públicas e por concessão, como previsto na Constituição do Estado. Em 31 de julho daquele ano, as concessões foram distribuídas através de sorteio, de acordo com as requisições dos beneficiários: 519 lotes urbanos e 35 suburbanos (Minas Geraes. Orgão Official Dos Poderes Do Estado, 1895b). Parte dos primeiros ocupantes dos subúrbios 
eram famílias privilegiadas, demonstrando que os subúrbios também eram escolhidos pelos mais ricos, e não somente o lugar "que sobrou" para os pobres. De acordo com uma lista publicada por Joaquim Lima, no Almanack da Cidade, de 1900, o primeiro prefeito de Belo Horizonte, Adalberto Diaz Ferraz, residia à época na zona suburbana, na rua do Chumbo, bem como Francisco Bressane de Azevedo, o diretor da Imprensa Oficial (Aguiar, 2006, p. 162).

Em 5 de julho do mesmo ano, o primeiro leilão de lotes listou aqueles à venda nas Seções I e II, próximas à Estação Central. Mais tarde, outro leilão lançado no dia 6 de novembro determinou preços mínimos para cada grupo de lotes, nas Seções I, II, III, IV, V, VII e IX. Somente um ano depois, em julho de 1896 , lotes suburbanos foram colocados à venda, também na forma de leilão, nas Seções I e VI. É significativo que dois principais aspectos eram considerados pela comissão, ao escolher a oferta vencedora: o preço oferecido e o tempo estimado para a construção. Logo, a rapidez da construção era valorizada, uma vez que havia pressa para que a cidade se materializasse.

Entretanto, de acordo com o relatório da Comissão Construtora de 1896, até a data de 10 de agosto daquele ano, somente 135 lotes haviam sido vendidos, dos 2.518 colocados à venda (Le-Ven, 1977, p. 34). Mais tarde, no mesmo mês, o governo reconheceu que o sistema de leilão público não estava sendo eficiente, atrasando a construção da capital. ${ }^{10} \mathrm{O}$ decreto n. 959, promulgado no dia 20 de agosto de 1896, autorizou o chefe da CCNC, Aarão Reis, a realizar vendas diretas de qualquer lote marcado na planta aprovada, seja na zona suburbana ou na urbana. As propostas deveriam ser enviadas à CCNC, baseadas nos preços praticados para lotes similares nos leilões anteriores. É importante observar que, apesar de todo o perímetro estar disponível para venda, apenas uma faixa para 30.000 habitantes seria construída pela Comissão no primeiro momento, enquanto o restante - o que inclui a zona suburbana - seria construído mais tarde, à medida que a cidade desenvolvesse. Porém, não estava claro quando isso iria de fato ocorrer. Assim, é possível que lotes tenham sido vendidos sem que suas localizações estivessem devidamente marcadas e sem a devida urbanização, reforçando as diferenças entre as zonas.

Apesar de não haver um zoneamento propriamente definido - além das categorias gerais urbano, suburbano e rural -, a região no entorno da Estação Central estava destinada a ser o centro da cidade. Em uma nota pública anunciando a realização do primeiro leilão de lotes, em 11 de julho de 1895, os lotes dessa área foram destacados:

alguns, situados nas proximidades da estação Central, nas ruas e avenidas que a ligarão com o centro da futura cidade e nas proximidades do Mercado, se acham em magnífica posição para commércio, fábricas e grandes depósitos; outros situados na grande avenida Afonso Pena - ou em suas proximidades e na do Parque estão destinadas para aprasíveis residências, com esplêndida vista para a estação, egreja e outros pontos". (Leal, 1895)

Os preços praticados nessas áreas eram mais altos, devido aos serviços de infraestrutura já realizados, o que incluía significativos cortes e aterros.

A maioria das pesquisas históricas de Belo Horizonte realizadas até o momento teve como foco a implementação de sua parte central, a zona urbana, com seu traçado geométrico e edifícios públicos, enquanto poucos 
estudos foram dedicados ao restante do território da cidade. Uma importante camada negligenciada por essa historiografia é o desenvolvimento suburbano (Aguiar, 2006).

Nos debates a respeito do plano original para a cidade, as zonas suburbana e rural são comumente mencionadas de maneira breve, como complementares à mais importante zona urbana. Na medida em que as análises vão além do plano para descrever e compreender o desenvolvimento urbano de Belo Horizonte depois de sua inauguração, os subúrbios são frequentemente descritos como desorganizados e não planejados, em contraste à parte central organizada geometricamente. Tendo crescido de maneira caótica e espontânea (Paula e Monte-mór, s/d), foram ocupados pela população mais pobre e pelos moradores do Arraial expulsos da nova cidade, segundo essas análises.

A tese doutoral de Tito Aguiar (2006) é uma exceção nesse contexto, dedicando-se inteiramente a uma cuidadosa análise do planejamento e da ocupação dos subúrbios de Belo Horizonte. Esse trabalho foi um importante passo para a desconstrução de representações consolidadas da cidade, principalmente no que diz respeito às primeiras décadas de ocupação (até os anos 1940). A primeira representação que Aguiar desconstrói é aquela do subúrbio não planejado, em contraste ao centro geometricamente organizado. A segunda está relacionada à interpretação do plano de Aarão Reis como elitista, levando a intensas segregações socioespaciais, entre um centro equipado para os influentes e um subúrbio precário para os pobres. Tais discussões serão aprofundadas mais adiante, com o objetivo de desvelar algumas das muitas práticas e instrumentos que construíram os subúrbios de Belo Horizonte, e como estas se diferenciam daquelas da área central. A discussão irá demonstrar como a divisão urbano/suburbano vai muito além da forma urbana e de estereótipos de relações centro/ periferia, como não somente uma separação física no mapa, mas, sobretudo, vivida cotidianamente nas práticas, tolerâncias e diferenciações estéticas.

\section{Distinções urbano-suburbanas}

Além dos evidentes contrastes morfológicos, 0 que mais se destaca na historiografia de Belo Horizonte, em respeito às diferenças entre urbano e suburbano, é a distribuição de classes sociais. Alguns autores atribuem a histórica segregação socioespacial em Belo Horizonte ao seu plano original, que contrasta uma zona urbana ordenada, equipada e elitista com um subúrbio precário e não planejado (Gomes e Lima, 1999; Le-Ven, 1977; Magalhães e Andrade, 1989). Após cuidadosa análise sobre a questão, uma das conclusões parciais de Aguiar (2006) é de que "a gestão dos espaços da nova cidade, ao longo de suas três primeiras décadas de vida, estabeleceu efetivamente a segregação social, ainda que esta [...] não estivesse prevista no plano da CCNC"11 (p. 207). Como apontado por Guimarães (1991), o principal objetivo do plano era de fato acomodar o aparato estatal e seus funcionários, como capital administrativa. Refletindo as tendências do momento, o plano não apontou um local específico para residência da classe trabalhadora, o que não era considerado uma responsabilidade do Estado. Além disso, lotes foram concedidos aos proprietários de casas em Ouro Preto como medida compensatória além de compor uma estratégia para mitigar as resistências à mudança da capital. 
Uma comparação entre o plano de 1895 e a planta cadastral de 1928-1929 não deixa dúvidas a respeito dos contrastes e hierarquias entre as zonas urbana e suburbana, da concepção à implementação. De um lado, a zona urbana continha os edifícios públicos mais importantes, os parques e as praças, e foi cuidadosamente planejada e construída majoritariamente por intervenção pública. De outro lado, a zona suburbana era composta pela justaposição de distintos fragmentos de tecido urbano, contendo equipamentos tipicamente periféricos, tais como hipódromo, matadouro, cemitério e estação de tratamento de esgoto. Todavia, descrever o subúrbio de Belo Horizonte como não planejado, desordenado ou de desenvolvimento espontâneo, como os historiadores mencionados o fizeram, apresenta uma visão muito limitada da questão. Torna-se necessário, então, desvelar as lógicas de seu desenvolvimento, compreendendo os processos de construção e ocupação, orquestrados por diversas racionalidades para além do plano, incluindo as camadas sociais, econômicas e legislativas.

Na tentativa de organizar a ocupação e a construção de edifícios privados na cidade, a legislação urbana incipiente em Belo Horizonte agiu primordialmente em duas frentes. De um lado, regulou a concessão de lotes para funcionários do estado e proprietários de Ouro Preto, como determinado pela lei n. 3 Adicional à Constituição. De outro, com o objetivo de a cidade materializar-se rapidamente, e de forma organizada, estabeleceu-se uma série de regulações urbanas que iam além das diretrizes gerais estabelecidas pelo plano inicial.

Em tais regulações, a primeira menção documentada da distinção entre "urbano" e "suburbano" é usada para diferenciar edifícios e não zonas propriamente ditas. 0 decreto n. 803 de 1895, ao regular a venda de lotes, declara em seu 8 o artigo que "Os lotes destinados às edificações urbanas e suburbanas serão vendidos em hasta pública [...]"(Minas Geraes. Orgão Official Dos Poderes Do Estado, 1895a). Mais adiante, no 15 - artigo, os adjetivos "urbano" e "suburbano" são usados para caracterizar lotes, determinando que nenhuma pessoa poderia comprar "mais de vinte lotes urbanos, de dez suburbanos, ou de vinte entre os de uma e outra espécie" (ibid.). No artigo 27, as distinções entre as regras para construções urbanas e suburbanas já são mais definidas. De acordo com o artigo, o comprador de lotes urbanos deveria construir dentro de quatro anos e gradear ou ajardinar a frente do lote dentro de dois anos. Para os lotes suburbanos, os prazos eram os mesmos para a construção, mas era necessário instalar gradil ou muro dentro de apenas um ano.

O plano de Aarão Reis foi aprovado quatro meses após esse decreto, apresentando as zonas urbana, suburbana e rural organizadas concentricamente. A ordem dos fatos sugere que o zoneamento proposto por Reis tenha sido, de fato, um reflexo do decreto n. 803, senão elaborados concomitantemente. No entendimento de Guimarães (1991), a concepção de uma zona urbana ocupada por quintas e chácaras teria sido inspirada pelo padrão suburbano já existente no Rio de Janeiro. Assim, a distribuição desigual de pessoas e de recursos entre essas zonas não deve ser atribuída somente ao zoneamento proposto, sendo, na verdade, a consequência de um longo processo no qual os padrões de segregação social já haviam se consolidado como um habitus (Bourdieu, 1990), bem antes da intervenção de Aarão Reis.

Como mencionado anteriormente, a CCNC iniciou as expropriações das casas do Arraial em 1894, forçando sua população a 
Figura 1 - 0 plano de 1895 sobreposto à planta cadastral do antigo arraial

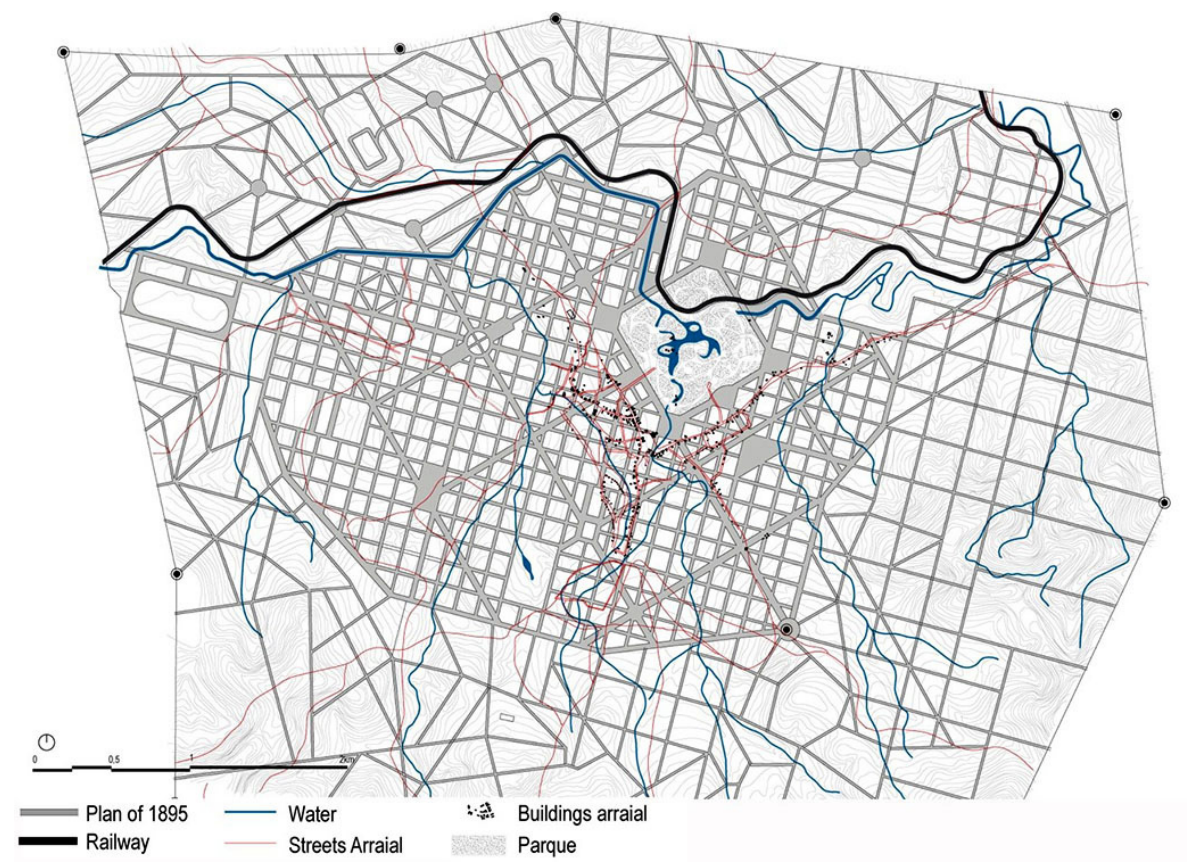

Fonte: a autora, em 2019.

mudar-se para a margem oposta do vale do Ribeirão Arrudas, fora dos canteiros de obras. No plano da cidade, a primeira área a ser construída para 30.000 habitantes ocupava uma faixa entre duas avenidas paralelas na zona urbana, tendo a avenida Afonso Pena no centro. Como demonstrado na Figura 1, essa área central "coincide" com a (ou melhor, se sobrepõe à) vila preexistente, requerendo sua rápida demolição. Assim, uma das primeiras consequências do plano foi o despejo imediato da população local de suas casas que, senão demolidas, foram rapidamente ocupadas pelos engenheiros como residências ou escritórios, à medida que o arraial era transformado em um canteiro de obras (Barreto, 1996).
Dessa forma, a população expulsa mudou-se para uma área mais elevada na margem oposta do Ribeirão Arrudas, ocupando o que viria a ser futuramente a zona suburbana, antes mesmo que fosse oficialmente projetada como tal por Aarão Reis e a CCNC (Dias, 1897). Uma das formas de compensação financeira aos moradores do arraial era a troca da propriedade expropriada por um lote urbano ou suburbano. Não se sabe como as casas foram avaliadas, mas os eventos demonstraram que os lotes na zona urbana eram vendidos a preços mais altos do que lotes maiores na zona suburbana (ver mais adiante). Ainda, as casas seriam trocadas por lotes apenas, necessitando a mobilização de capital para se construir 
uma nova casa. De acordo com Guimarães (1991), a maioria dos proprietários optou por compensação em dinheiro ao invés de lotes. Entende-se, portanto, que os moradores do Arraial tenham ocupado áreas fora da cidade, usando a compensação financeira para construir novas casas ou comprar lotes suburbanos. Estes eram mais baratos e maiores, e ainda mais compatíveis com o estilo de vida camponês preexistente, na medida em que também as regulações urbanas permitiam a pequena lavoura e a criação de animais.

Como muitos autores argumentaram (Le-Ven, 1977; Guimarães, 1991; Penna, 1997; Aguiar, 2006), um dos diversos fatores que levaram à exclusão da população mais pobre da zona urbana foi o elevado preços dos lotes, supostamente resultante de uma tendência natural do livre mercado de terras, em que lotes são valorizados de acordo com localização e infraestrutura. Entretanto, tal valorização partiu, em primeiro lugar, de uma clara decisão governamental, na medida em que o Estado agiu, em Belo Horizonte, como comprador, regulador e vendedor de terras. Os decretos citados acima determinaram de antemão que os preços dos lotes seriam decididos pelo Estado, de acordo com a localização e proximidade a equipamentos públicos. O governo estaria, portanto, predeterminando ou ainda intencionalmente impulsionando tal tendência de mercado. Naturalmente, os lotes na zona urbana eram mais caros, pois a região recebeu consideráveis esforços e investimentos, contendo os lotes reservados para os edifícios públicos mais importantes, já em construção à época da venda dos lotes. Ainda, nos primeiros leilões de lotes, os preços foram sugeridos pelos potenciais compradores, na forma de ofertas. Assim, os preços elevaram-se conforme os interesses cresciam.
Mais tarde, outras regulações urbanas reforçaram as distinções entre as zonas urbana e suburbana. O primeiro Código de Posturas para a cidade, lançado pelo decreto n. 1211, de 30 de outubro de 1898, revisa e reafirma algumas premissas das legislações anteriores. De acordo com o artigo 5, os preços dos lotes não mais oscilariam conforme sua localização ou pelos lances de leilão, mas estariam fixados em $\$ 500.000$ (quinhentos mil réis) para lotes urbanos, com áreas semelhantes, e \$30 (trinta réis) por metro quadrado para lotes suburbanos, estes com superfícies bem diversas. Exceção foi feita aos lotes já aterrados perto da Estação Central e da Praça da Estação, onde o metro quadrado custaria entre $\$ 2.000$ e $\$ 3.000$. Exceto os lotes triangulares, localizados nas interseções das diagonais, o lote urbano padrão tinha 600 metros quadrados, resultando na relação de $\$ 833$ (oitocentos e trinta e três réis) por metro quadrado, ou seja, menos da metade dos preços praticados na região da Estação Central ${ }^{12}$ e aproximadamente trinta vezes mais caros do que os lotes suburbanos.

As diferenças de preços entre as terras urbanas e suburbanas não estavam relacionadas apenas à localização, pois refletiam o investimento em topografia, esgoto, pavimentação e arborização. Uma vez que quase nenhum investimento foi direcionado aos subúrbios pelo menos nas primeiras duas décadas, seus lotes eram consideravelmente mais baratos. De acordo com essa nova regulação, o período para construção nessa zona foi reduzido significativamente: compradores teriam apenas seis meses para iniciar a construção e doze meses para completá-la, um prazo extensível por não mais que seis meses, a juízo do prefeito. 
Outras distinções entre as zonas estavam relacionadas aos usos e programas. Ainda segundo o decreto n. 1211, de 1898, eram proibidos, na zona urbana, chiqueiros e estábulos de vacas, permitindo somente cocheiros para animais de sela e tração, ou seja, somente aqueles necessários ao transporte de pessoas e objetos.

Algumas medidas foram direcionadas à assistência aos pobres de maneira a dar suporte à integração deles à nova cidade. Moradores de cafuas e operários estavam isentos da taxa de escritura na compra de novos lotes. ${ }^{13}$ Além disso, os proprietários suburbanos poderiam ser liberados de cumprir algumas exigências dos parâmetros construtivos quando a situação financeira não permitisse, também a juízo do prefeito. Através desse decreto, a ocupação dos subúrbios foi flexibilizada, em contraste à zona urbana, estritamente regulada.

Entre 1900 e 1902, 19 decretos regularam os serviços municipais e estabeleceram normas para guiar o uso e a ocupação na cidade, no esforço de moldar as práticas cotidianas dos novos moradores de Belo Horizonte (Aguiar, 2006, p. 189). Em 1901, um novo Código de Posturas entrou em vigor, reforçando algumas regulações antigas e fornecendo normas detalhadas para condutas, usos e parâmetros construtivos, incluindo detalhes sobre procedimentos, soluções técnicas e qualidade dos materiais. 0 artigo 23 reforça o que as legislações anteriores deixaram implícito que edifícios estariam classificados entre urbanos e suburbanos. De fato, o decreto n. 1453 de 27, de março de 1901 (Minas Gerais, 1901), estabeleceu diferenças significativas entre edifícios urbanos e suburbanos, de acordo com a zona em que seriam construídos. Algumas serão aqui destacadas, com atenção especial àquelas que resultaram, direta ou indiretamente, em segregação socioespacial.
Talvez a mais significativa adição às normas de condutas seja a proibição, na zona urbana, de cortiços, pensões ou qualquer forma de habitação coletiva, exceto hotéis. Essa modalidade era, na maioria das vezes, a única alternativa possível para os pobres e os imigrantes envolvidos na construção da cidade. Antes de sua inauguração, agrupamentos de pequenas casas ocupando o mesmo lote e alugadas a preços baixos já estavam sendo construídos nos subúrbios (Barreto, 1996), p. 638). Esse tipo de habitação, ou seja, casas de aluguel barato, estaria, então, relegado à zona suburbana.

Em geral, a estética arquitetônica recebeu especial atenção na legislação, principalmente na zona urbana. Além de contribuírem para o "embelezamento" da cidade, era esperado que os edifícios preenchessem o espaço urbano de maneira harmoniosa. Na zona urbana, as fachadas deveriam ter pelo menos seis metros de altura e sete metros de comprimento, ocupando, no mínimo, 2/3 do lote (Minas Gerais, 1901). A frente deveria ser ajardinada e fechada com gradil, enquanto, na zona suburbana, poderiam ser fechadas com cercas-vivas, madeira ou arame. 0 artigo 31 dispõe que 0 estilo arquitetônico não seria determinado, mas, visando ao embelezamento da cidade, estaria sujeito à análise da prefeitura. Porém, outro artigo exigia que telhados fossem cobertos por platibandas ou frontões artísticos, indicando forte inclinação ao estilo eclético, também escolhido para os edifícios públicos e para as casas de funcionários. Isso significava uma total rejeição ao estilo colonial, predominante em Ouro Preto. Ainda, as fachadas deveriam ser pintadas com cores, sendo o branco proibido, o que também vai contra a estética de Ouro Preto. 
Outras exigências específicas para a zona urbana regularam a qualidade dos materiais usados na construção privada de maneira a garantir o embelezamento da parte central da cidade e uma salubridade adequada. Ao mesmo tempo, tais medidas também tinham o efeito de evitar a ocupação por uma população mais pobre nessas áreas. 0 uso de materiais precários, como paredes de adobe ou madeira e telhados de zinco ou palha, era permitido somente na zona suburbana. 0 artigo 74 resume tais intenções: "Não é permitido, principalmente nas construções urbanas, o emprego de material de má qualidade" (ibid.). Se utilizados, estariam sujeitos a multa ou mesmo demolição. Edificações abandonadas estavam sujeitas às mesmas penalidades. É transparente, portanto, a importância dada à imagem da cidade em formação nesses primeiros anos, uma vez que o projeto político havia prometido a construção de uma cidade organizada, símbolo do progresso e civilização para o estado de Minas Gerais.

0 artigo 72 do mesmo código traz uma importante reflexão a respeito da ocupação de diversas regiões da cidade. De acordo com o texto, nenhuma edificação poderia ser construída em locais com aterro recente, exigindo, no mínimo, cinco anos de consolidação, exceto se a fundação fosse assentada sobre terreno natural (ibid.). Os trabalhos topográficos começaram por volta de 1895, quando o plano foi aprovado, e continuou por muitos anos nas áreas próximas à Estação Central (a porção sudoeste na zona urbana só foi urbanizada a partir dos anos 1920). Tal fato significa que, por um longo período, extensas áreas estiveram inadequadas para construção, exceto se utilizadas técnicas dispendiosas de fundação. Além disso, nenhuma edificação poderia localizar-se nas proximidades de córregos, devendo manter uma distância de ao menos setenta metros, exceto se as margens fossem reforçadas por paredes de contenção (ibid.). Isso significa que, para que tais condições fossem atendidas, a ocupação (oficial) de extensas áreas só seria possível após a canalização dos córregos. É sabido, porém, que muitas pessoas já estavam ocupando as margens de córregos, como o do Leitão, desde o início da construção da cidade (Guimarães, 1991, p. 70).

\section{Exceções}

Como exposto, muitas regulações foram impostas à zona urbana, no intuito de se formar uma cidade bonita, ordenada e higiênica, que atendesse às altas expectativas da nova capital, e não um assentamento temporário. Apesar de projetada para ser a capital do estado, esperava-se muito mais de Belo Horizonte do que ser somente um centro administrativo. Substituir Ouro Preto significava preencher as lacunas que esta havia deixado, constituindo-se como um centro logístico e político do estado, equipado com um centro industrial impulsionador de desenvolvimento econômico. Isso implicava que sua população não seria composta apenas de altos funcionários, mas também da classe trabalhadora, a primeira a construir a cidade e, mais tarde, a formar a mão de obra industrial e de serviços, comércio, etc. É importante lembrar que a escravidão foi abolida somente alguns anos antes da fundação da cidade, resultando em uma massa de pobres, desempregados ou trabalhadores em situação precária. Um exemplo disso é o fato de que, em 1900, boa parte do comércio era realizada por vendedores de rua, tal como registrado no Almanack da cidade daquele ano, que entregavam carne, pão, legumes e outras provisões de porta em porta (Lima, 1900). 
A população pobre não foi totalmente ignorada pelo governo ou pelo plano de Aarão Reis, apesar de largamente negligenciada. 0 artigo 60 da lei n. 3 de 1893 menciona brevemente que o estado deveria promover a construção de casas em condições sanitárias e a alugueis baratos para os trabalhadores (CCNC, 1895). Porém, muito mais atenção e recursos foram direcionados aos funcionários do estado, para quem lotes foram concedidos e casas foram construídas, em pagamentos mensais. Em 1896, a CCNC construiu barracões temporários para abrigar cerca de 200 pessoas, o que foi ainda insuficiente diante do grande número de imigrantes e construtores com suas famílias (Guimarães, 1991, p. 69). Entre 1896 e 1897, 1.111 licenças foram concedidas para a construção de barracões temporários (ibid.).

Ações direcionadas à habitação para os pobres e trabalhadores responderam, portanto, às circunstâncias do momento ao invés de fazerem parte de um planejamento. Ao planejar a cidade, Aarão Reis concentrou-se na geometria das ruas, na distribuição de praças e edifícios, na divisão racional dos lotes, em suma, na forma urbana e na técnica. No papel de engenheiro encarregado da construção - apesar de que breve -, sua principal preocupação foi cumprir sua missão, o mais logo possível (Dias, 1897). A distribuição das classes sociais provavelmente não era sua preocupação direta, tampouco o era esperado, na função de engenheiro chefe. 0 testemunho dado pelo padre Francisco Martins Dias, republicado no registro histórico de Belo Horizonte mais consultado - Belo Horizonte: história média, de Abílio Barreto (1996) -, transformou Aarão Reis em uma figura impopular, retratando-o como um homem frio e racional. Martins teria ouvido o próprio Aarão Reis dizer que não queria mais ver os moradores do Arraial nas áreas que iriam se tornar as zonas Urbanas e Suburbanas e que eles deveriam deixar o local (ibid., p. 71). Além de planejador da cidade e engenheiro chefe, ele ainda ficou encarregado das expropriações. Isso mostra que o engenheiro se tornou a personificação das ações do Estado em Belo Horizonte e explica o porquê de tanta responsabilidade sobre o plano ter sido atribuída à sua pessoa. De fato, ele planejou a cidade com três zonas simultâneas, com características diversas, e, apesar de não declarado publicamente, capazes de abrigar uma ampla diversidade de pessoas de acordo com as categorias de urbano, suburbano e rural. Apesar de uma população mais rica ter desejado morar nos subúrbios, em quintas ou grandes lotes, o contrário não poderia ocorrer, uma vez que a zona urbana não estava acessível para os mais pobres. As normas e os preços estabelecidos para essa zona, além da sucessão de leis, decretos, leilões e, mais tarde, a ação do mercado, tornaram-na proibitivas para os pobres.

Durante os primeiros anos da construção, barracões improvisados foram tolerados nas zonas urbana e suburbana (Guimarães, 1991). Mesmo diante dos esforços para concessão de alvarás, a ocupação informal alastrava-se, com cafuas e barracos surgindo por todo lado. Com o avanço das obras, os habitantes dos aglomerados foram sendo expulsos e se assentando em outros lugares, cada vez mais distantes. Durante as primeiras décadas, houve um ciclo constante de despejos e reassentamentos por toda a cidade. A primeira favela a se formar foi a o Alto da Estação, já nos primeiros anos da capital, ocupando o morro atrás da Estação Central. Uma vez que a urbanização dessa área demorou a ser realizar, a parcela 
entre a ferrovia e a avenida do Contorno foi a única parte da zona urbana que não foi implementada de acordo com o plano.

$\mathrm{Na}$ medida em que avançavam as ocupações irregulares, as autoridades foram obrigadas a agir no sentido de alojar essa população. Não obstante os preços mais baixos e as normas mais flexíveis, a zona suburbana ainda era inacessível para grande parte da população (ibid.). Aqueles que não podiam pagar continuavam a ocupar as áreas ainda não urbanizadas, tais como as margens dos córregos e os morros - um padrão persistente nos dias atuais. Apesar da lei de 1893 prever a construção de casas para trabalhadores, nenhuma ação foi tomada nesse sentido até 1902.

Nesse ano, características suburbanas transformaram parte da zona urbana. Através do decreto n. 1516 daquele ano, o governo estabeleceu condições especiais para a concessão de lotes para operários e para indústrias. De acordo com o artigo 23, uma zona operária deveria ser instalada na VIII Seção da Zona Urbana (hoje bairro Barro Preto), imediatamente ao lado da faixa a ser construída pela CCNC para 30.000 habitantes (Minas Gerais, 1902). Sua viabilidade significou uma série de exceções às normas vigentes - diante da realidade social, as adaptações eram inevitáveis; não foram as últimas nem as primeiras. A VIII Seção foi então transformada em zona suburbana, significando um relaxamento das normas para concessão de lotes e dos parâmetros para ocupação. Mais tarde, em 1909, o governo criou, através do decreto n. 2846, uma zona operária nessa zona, a ser ocupada exclusivamente por operários da indústria. 0 decreto modificou a legislação anterior, reduzindo o número de lotes a serem divididos e distribuídos de forma gratuita de 43 para apenas 17. Porém, um certo grau de civilidade era necessário, uma vez que só teriam direito à concessão de lotes nessa área os que pudessem provar:

a) ser operários, isto é, tirarem sua subsistência de trabalhos manuaes, [...]; b) ter residência na Capital durante, pelo menos, dois annos antes da data do seu requerimento pedindo a concessão do lote, e ter exercido sua arte ou officio ininterruptamente durante esse tempo; c) ter bons costumes e ser dedicado ao trabalho. (Minas Gerais, 1909 apud Plambel, 1979, p. 66).

0 artigo ainda acrescenta: "As condições das letras a e b serão provadas por um atestado de três pessoas conceituadas, a juízo do prefeito; a da letra c, por meio de um certificado de autoridade policial" (ibid.).

No entanto, os investimentos em infraestrutura não corresponderam a essas medidas, uma vez que água, esgoto e energia não foram implantados nessa área nos primeiros anos. Rapidamente, esse bairro apresentou as piores condições sanitárias da capital (Aguiar, 2006, p. 186).

Em 1919, a lei n. 178 autorizou a prefeitura a estabelecer as Vilas Operárias, que consistiam na subdivisão de lotes em parcelas menores e, portanto, mais baratas para as classes operárias (Belo Horizonte, 1919). Contudo, sabe-se, através dos relatórios dos prefeitos dos anos seguintes, que as divisões ilegais de lotes continuaram e ocorrer na zona suburbana (Belo Horizonte, 1937), resultando em uma forma urbana divergente do plano inicial.

0 primeiro loteamento operário aprovado e construído pelo governo foi a vila Concórdia em 1928. Apesar dos esforços em promover habitação e loteamentos para todas as 
classes, o problema do preço dos lotes permaneceu. No relatório do Presidente do Estado de 1925, ele afirma que

\begin{abstract}
A ação da prefeitura [...] tem sido benéfica ao desenvolvimento da cidade, facilitando a acquisição de terrenos, para a construção de prédios, às diversas classes sociaes, principalmente aos operários e funccionários, de par com a consideração especial dada à creação de indústrias. Não fora isto, o progresso da Capital ver-se-ia entravado, por longos anos, porque, com a valorização sempre crescente da propriedade particular, tem se tornado quase impeditivo sua acquisição, ou a construção de prédios, principalmente para a residência, por parte das classes menos favorecidas. (Minas Geraes, 1926)
\end{abstract}

Outro elemento que teve papel fundamental na ocupação dos subúrbios foi o estabelecimento das colônias agrícolas nas zonas suburbana e rural. Promovidas pelo estado, não faziam parte do plano de 1895 de Aarão Reis, mas foram implementadas simultaneamente à construção da cidade, sobrepondo uma nova camada ao modelo concêntrico idealizado pelo engenheiro. Com a implementação dessas colônias, manchas agrícolas foram superpostas à grelha desenhada por Aarão Reis; uma nova subdivisão de terras foi aplicada, seguindo uma lógica rural, de maneira que as divisões de propriedade foram organizadas ao longo dos córregos, onde a terra era mais fértil, formando longas faixas distribuídas perpendicularmente aos corpos d'água.

As colônias assim foram denominadas: Carlos Prates, a maior a oeste, ao norte Córrego da Mata (mais tarde renomeada como Américo Werneck), Bias Fortes a leste e Adalberto Ferraz, ao sul. Planejadas e implementadas pelo Estado (1898-1899), as colônias contrastam-se em relação ao plano de Reis, que tinha desenhado essas áreas como zona suburbana, bem separada da zona rural, no anel mais periférico. Contudo, tais colônias foram implementadas em áreas já ocupadas por fazendeiros antes de serem expropriadas para a construção da cidade. Sua designação como área agrícola, de fato, reforçou as características históricas da área, antes que fossem marcadas por Reis como subúrbios, porém substituindo seus habitantes por imigrantes.

Em 1912, ${ }^{14}$ as colônias, recentemente emancipadas pelo estado, ${ }^{15}$ foram oficialmente incorporadas à zona suburbana, não mais pertencendo ao projeto estatal de agricultura, e a partir de então sujeitas às regulações municiais de Belo Horizonte. A prefeitura seria, a partir desse momento, responsável pela pavimentação das ruas e construção de praças. Aos poucos, as longas faixas de terra foram subdivididas com a adição necessária de ruas e espaços abertos. Visto que as áreas agrícolas ocupavam grande parte da zona suburbana, sua forma urbana resultante está mais próxima do que podemos chamar de suburbanização espontânea. Contudo, pertencer oficialmente ao município não significou a implementação da infraestrutura necessária.

Sob influência da presença de italianos, os primeiros a formarem associações na cidade, movimentos de trabalhadores começaram a surgir nessas áreas, reivindicando seus direitos à habitação e melhores condições de trabalho e de vida. Na análise de Le-Ven (1977), as exigências feitas pelos membros de clubes de trabalhadores e de outras associações levaram a uma prática de protestar por melhores infraestruturas nos precários bairros operários. Nos anos seguintes, essa prática se tornou 
um procedimento comum: áreas suburbanas eram subdivididas e vendidas sem qualquer infraestrutura no mercado privado, e depois os residentes pressionavam a municipalidade através da mídia ou influência política para a instalação delas. Agrupados em associações de bairro, residentes do Calafate garantiram a implementação de bondes, em 1911, e as associações da Floresta e da Lagoinha protestaram pelo abastecimento de água no mesmo período (ibid.).

Logo, em contraste à zona urbana, na qual a infraestrutura básica foi instalada e a salubridade e a ordem prometidas foram garantidas, nos subúrbios e áreas rurais urbanizadas, estas foram conquistadas gradualmente pelos residentes através de pressão exercida às autoridades ou mesmo através da autoconstrução. Nas áreas urbanas, bem como nas suburbanas, vimos a histórica ocupação informal ao longo de córregos e morros, nos quais a construção da cidade tardou a acontecer. As condições anti-higiênicas de tais assentamentos contrastavam-se com as ambições da capital.

\section{Conclusões}

A análise deste artigo permitiu apreender que o plano de Belo Horizonte de 1895 previu três ambientes distintos e fisicamente separados, ao dividir o perímetro da cidade em urbano, suburbano e rural. O primeiro deveria abrigar o aparato administrativo do Estado de Minas Gerais e as residências dos funcionários, cuidadosamente projetadas e construídas para formar o melhor exemplo da capacidade do poder do Estado, da técnica da engenharia daquele tempo, tendo como premissa ordem, progresso e higiene. Como nenhuma cidade é constituída unicamente de corpo administrativo, uma zona suburbana deveria acomodar outras funções, usos e pessoas, estilos de vida "menos urbanos", com uma organização espacial menos rígida, lotes maiores e quintais. Finalmente, a zona rural deveria abastecer a capital, mantendo as características do extinto Arraial de Bello Horisonte, ou seja, de pequenas fazendas.

Contudo, a análise demonstrou como, com o tempo, uma sobreposição de planos, regulamentos, leis e ações reorganizou as constelações urbanas, suburbanas e rurais em termos de espaço e relações sociais. Enquanto o rural subverteu o urbano e vice-versa, com a implementação das colônias agrícolas e sua posterior urbanização, o suburbano também inverteu o urbano com as exceções feitas aos trabalhadores e a tolerância aos aglomerados informais. O primeiro espaço da cidade materializou-se como uma constelação de diferentes iniciativas de urbanização e construção, apesar da definição do plano de três zonas. Isso resultou, por um lado, de constantes mudanças na manutenção, regulação e programação do território e, por outro, das lógicas mercadológicas e da apropriação de terrenos vazios.

A análise também evidenciou que a divisão de classes em Belo Horizonte vai muito além de uma relação centro-periferia, na qual o centro se torna inacessível aos pobres. É evidente que os subúrbios receberam investimentos bem diversos, especialmente se considerarmos a ausência de espaços públicos e edifícios administrativos. Do contrário, era o lugar dos programas indesejados, como cemitério, matadouro e hipódromo. Através da restrição de usos, condutas, tipologias, o subúrbio tornou-se o receptáculo do que foi visto como 
impróprio para a cidade "oficial", que deveria ser representada pela imagem da zona urbana, com seus edifícios públicos e casas alinhadas. Os subúrbios eram o lugar dos cortiços, das casas coletivas operárias e dos animais. Como tempo, a divisão urbano/suburbano de Belo Horizonte tornou-se o resultado de muitas camadas de distinção em vigor desde o início, levando à enorme segregação socioespacial hoje vista.

Sua atual imagem é o resultado da implementação da grelha, ou da falta dela, do investimento seletivo de infraestrutura básica, como esgoto, água e pavimentação - influenciando diretamente a saúde dos habitantes -, e da criação de um mercado imobiliário a partir do zero. Ganha nova textura com acumulação de leis e códigos de conduta, guiando as possibilidades de acesso e habitabilidade aqui e não ali, fazendo exigências materiais e estéticas no detalhamento das fachadas, jardins e materiais de construção. Restrições de uso, que refletem diretamente nas práticas cotidianas dos residentes também incluíam uns ao excluir outros. Finalmente, um jogo de permissões, tolerâncias e proibições funcionou de maneira a promover melhores condições de vida para uns, embora piores para outros.

\section{[I] https://orcid.org/0000-0002-7386-5764}

Universidade Federal de Ouro Preto, Escola de Minas, Departamento de Arquitetura e Urbanismo. Ouro Preto, MG/Brasil. pcapanema@gmail.com

\section{Notas}

(1) Ver Mumford (1961) e Rabinow (1995).

(2) No sentido de sobreposição, assemblage ou collage.

(3) Texto disponível em https://legis.senado.leg.br/norma/385366/publicacao/15820785.

(4) A grafia "Bello Horisonte" refere-se ao antigo arraial substituído pela nova capital. Esta recebeu o mesmo nome (por um breve período também chamada de "Cidade de Minas"), apesar de a grafia ter mudado para "Belo Horizonte", a versão atual. Para manter a distinção entre o Arraial de Bello Horisonte e a capital Belo Horizonte, ambas as formas serão mantidas.

(5) O relatório foi mencionado pelo sr. Manoel Eustachio, na sessão de 16 de maio de 1891 (O Jornal de Minas, 1891).

(6) As edições do $O$ Jornal de Minas, de novembro de 1890 até maio de 1891, estão disponíveis em: www.bn.gov.br.

(7) O Congresso Constituinte era um congresso temporário especialmente composto para a discussão e a votação da Constituição de Minas Gerais. 
(8) Tradução livre da autora. No original: we must remain agnostic about the connection between formal spatial order and social experience.

(9) Tradução livre da autora. No original: became a hotbed for innovation and a maelstrom of social, cultural and economic change as the new notions of speed, light, power and communications were constructed.

(10) De acordo com Singer, a renda da venda de lotes não seria suficiente para financiar a construção da cidade, não somente devido ao número reduzido de lotes vendidos até 1897, mas também aos preços baixos obtidos nos leilões, forçando o Estado a tomar sucessivos empréstimos, em 1895, 1896 e 1897, do Banco de Paris e da Holanda (1968, p. 220).

(11) O autor se refere aqui ao plano assinado por Aarão Reis, chefe da CCNC.

(12) Os lotes nessa região tinham diversas áreas, variando entre $450-525 \mathrm{~m}^{2}$, custando, portanto, entre $\$ 900.000$ e $\$ 1.575 .000$.

(13) Assim também para os lotes concedidos.

(14) Lei n. 55 de 1912 (Belo Horizonte, 1912).

(15) Até então, eram administradas pelo Estado. Após a emancipação, passaram a ser regulamentadas pelo município.

\section{Referências}

AGUIAR, T. F. R. DE (2006). Vastos subúrbios da nova capital: formação do espaço urbano na primeira periferia de Belo Horizonte. Belo Horizonte, Universidade Federal de Minas Gerais.

BARRETO, A. (1996). Bello Horizonte: memória histórica e descriptiva. História Média. Belo Horizonte, Imprensa Oficial Minas Geraes.

BONDUKI, N. G. (2004). Origens da habitação social no Brasil. Arquitetura moderna, Lei do Inquilinato e Difusão da Casa Própria. São Paulo, Estação Liberdade.

BOURDIEU, P. (1990). The Logic of Practice. Stanford/California, Stanford University Press.

BRASIL, R. F. do (1889). Decreto n. 7 de 20 de novembro. Disponível em: https://legis.senado.leg.br/ legislacao/ListaTextoSigen.action?norma=385366\&id=14225732\&idBinario=15820785.

CAPITAL (1893). Comissão d'Estudo das Localidades Indicadas para a Nova Capital: relatório. Rio de Janeiro, Imprensa Nacional.

CHOAY, F. (2005). O urbanismo. São Paulo, Perspectiva.

COMMISSÃO CONSTRUCTORA DA NOVA CAPITAL (1895). Revista Geral dos Trabalhos, v. 1: publicaçao periodica, descritiva e estatistica, feita com autorisação do governo do estado Minas Gerais. Rio de Janeiro. Disponível em: http://bdlb.bn.gov.br/acervo/handle/123456789/42264. Accesso em: 1 o jan 2018. 
DIAS, P. F. M. (1897). Traços Históricos e Descriptivos de Belo Horizonte. Belo Horizonte, Arquivo Público Mineiro.

FARIA, M. A. (1985). Belo Horizonte: Espaço Urbano e Dominação Política (uma abordagem histórica). Varia Historia, v. 1, n. 1.

GOMES, M. A. A. DE F.; LIMA, F. J. M. DE (1999). Pensamento e Prática Urbanística em Belo Horizonte 1865-1961. In: LEME, M. C. DA S. (coord.). Urbanismo no Brasil: 1865-1965. São Paulo, Nobel/ FAUUSP/Fupam.

GRAHAM, S.; MARVIN, S. (2001). Splintering Urbanism: networked infrastructures, technological mobiles and the urban condition. Nova York, Routledge.

GUIMARÃES, B. M. (1991). Cafuas, barracos e barracões: Belo Horizonte, cidade planejada. Instituto Universitário de Pesquisa do Rio de Janeiro.

LEAL, F. N. (1895). Nova Capital do Estado de Minas Geraes. Venda de Lotes. Minas Geraes. Orgão Official dos Poderes do Estado, 11 julho, p. 8.

LEMOS, C. B. (1998). A Cidade Republicana: Belo Horizonte, 1897-1930. In: CASTRIOTA, L. B. (org.). A Arquitetura da Modernidade. Belo Horizonte, IAB-MG, p. 310.

LE-VEN, M. M. (1977) Classes sociais e poder político na formação espacial de Belo Horizonte (18931914). Fafich-UFMG.

LIMA, J. R. de (1900). Almanack da Cidade.

LINHARES, J. N. (1905). Mudança da Capital. (Ouro Preto-Belo Horizonte). Belo Horizonte, Conselho da Medalha da Inconfidência.

MAGALHÃES, B. DE A.; ANDRADE, R. F. (1989). Belo Horizonte: um espaço para a república. Belo Horizonte, Universidade Federal de Minas Gerais.

MINAS GERAES. Orgão Official Dos Poderes Do Estado (1895a). Decreto n. 803, de 11 de Janeiro de 1895, 14 janeiro, p. 1.

(1895b). Nova Capital. Termo de sorteio dos lotes destinados aos proprietários de casas em Ouro Preto, 17 August.

MINAS GERAIS, E. de (1901). Decreto 1453 de 27 de março de 1901. Regulamento das construções, reconstruções e demolições de obras na Cidade de Minas. Belo Horizonte, Imprensa Oficial Minas Geraes.

(1902). Decreto 1516 de 2 de maio de 1902. Regula a concessão de terrenos às indústrias, associações e a venda a particulares. Belo Horizonte, Imprensa Oficial Minas Geraes.

MINAS GERAIS, O. E. de (1894). Decreto 680 de 14 de fevereiro de 1894. Regula o disposto no art. 2은 da Lei n. 3 de 17 de dezembro de 1893, adicional à Constituição do Estado.

MUMFORD, L. (1961) The City In History. Its Origins, Its Transformations, and Its Prospects. Nova York, Houghton Mifflin Harcourt.

O JORNAL DE MINAS (1891). Congresso Mineiro. Discurso Pronunciado pelo Sr. Manoel Eustachio na sessão de 16 de maio de 1891.

PAULA, J. A. DE; MONTE-MÓR, R. L. M. (no date) Formação Histórica: Três momentos da história de Belo Horizonte. Belo Horizonte. 
PENNA, A. D. (1997). Belo Horizonte: um espaço infiel. Varia Historia, n. 18, pp. 101-121.

PLAMBEL - Superintendência de Desenvolvimento da Região Metropolitana de Belo Horizonte (1979). O processo de desenvolvimento de Belo Horizonte: 1897-1970. Belo Horizonte, Plambel, v. 2, pp. 3-182.

RABINOW, P. (1995). French modern : norms and forms of the social environment. University of Chicago Press.

RESENDE, M. E. L. de (1974). Uma interpretação sobre a Fundação de Belo Horizonte. In: VII SIMPÓSIO NACIONAL DOS PROFESSORES UNIVERSITÁRIOS DE HISTÓRIA. Anais... São Paulo.

SALGUEIRO, H. A. (1997). Engenheiro Aarão Reis: o progresso como missão. Belo Horizonte, Fundação João Pinheiro.

(2001). Cidades capitais do século XIX: racionalidade, cosmopolitismo e transferência de modelos. São Paulo, Edusp.

SCOTT, J. C. (1998). Seeing Like a State: how certain schemes to improve the human condition have failed. New Haven and London, Yale University Press.

SINGER, P. (1968). Desenvolvimento Econômico e Evolução Urbana. Análise da evolução econômica de São Paulo, Blumenal, Porto Alegre, Belo Horizonte e Recife. São Paulo, Companhia Editora Nacional.

Texto recebido em 30/out/2020

Texto aprovado em 15/mar/2021 